\title{
Etiología del síndrome febril agudo en niños de 1 mes a 5 años hospitalizados en el Servicio de Urgencias del Hospital Universitario Hernando Moncaleano Perdomo de Neiva
}

\author{
Etiology of acute fever syndrome in children of 1 month to 5 years \\ of age hospitalized at the Emergency Department at Hernando \\ Moncaleano Perdomo University Hospital in Neiva
}

Paola A. Cáceres' ${ }^{1}$ Zulma K. Cifuentes², Doris Salgado³

\section{Resumen}

La fiebre en los niños es causa de muchas consultas con profesionales en salud comprometiendo principalmente a menores de 5 años y frecuentemente con etiología desconocida por profesionales y cuidadores. Objetivo: Determinar la etiología del síndrome febril agudo en niños de 1 mes a 5 años atendidos en el servicio de urgencias del Hospital Universitario Hernando Moncaleano Perdomo de Neiva entre julio de 2012 y junio de 2013. Materiales y métodos: Se llevó a cabo un estudio descriptivo, prospectivo en el Hospital Universitario Hernando Moncaleano Perdomo de Neiva, durante el periodo comprendido entre Julio de 2012 a Junio de 2013, en niños de 1 mes a 5 años, que ingresaron al servicio de urgencias pediátricas, a quienes se realizaron pruebas de laboratorio necesarias, incluyendoprueba rápida dengue, $(\lg G / \lg M$ + NS1 Ag) y Elisa IgM PANBIO ${ }^{\circledR}$, panel viral respiratorio y rota-test. Los datos fueron almacenados en hoja de cálculo de Excel, analizadosen el programa SPSS versión 20. Resultados: Del total de niños, 650 fueron incluidos. Se dividieron en dos grupos, uno con síntomas respiratorios (total 261) y otro sin síntomas respiratorios (total 389), distribuidos por orden en frecuencia así: Infecciones del tracto respiratorio, primer lugar, seguido por dengue, enfermedad diarreica aguda, infección tracto urinario, infecciones de piel y tejidos blandos y enfermedades exantemáticas. Conclusiones: Las infecciones virales se constituyen como la principal etiología del síndrome febril agudo en niños menores de 5 años.
Palabras clave: Pediatría, fiebre, fiebre del dengue, infecciones respiratorias.

\section{Abstract}

Fever in children causes many consultations with health professionals involving primarily children under 5 years of age and often with unknown etiology for practitioners and caregivers. Objective: to determine acute fever syndrome in children of 1 month to 5 years of age attended at the emergency department at Hernando Moncaleano Perdomo University Hospital in Neiva, between July 2012 and June 2013. Materials and methods: it was carried out a prospective, descriptive study at Hernando Moncaleano Perdomo University Hospital in Neiva, from July 2012 to June 2013, in children whose age ranged from 1 month to 5 years of age, admitted at the pediatric emergency unit. These children underwent lab tests, including dengue rapid test, $(\lg \mathrm{G} / \lg M+\mathrm{NS} 1 \mathrm{Ag})$ and Elisa $\lg M$ PANBIO ${ }^{\circledR}$, respiratory viral panel and rotating-test. Data were stored in Excel spreadsheet and analyzed using SPSS version 20 program. Results: from the total, 650 children were included. They were divided into two groups; one with respiratory symptoms (total 261) and the other without respiratory symptoms (total 389), distributed on a frequency basis as follows: respiratory tract infections, dengue, acute diarrheic disease, urinary tract infection, skin disease, and soft tissues, and rash diseases. Conclusions: viral infections are the main etiology of acute fever syndrome in children under 5 years of age.

Keywords: Pediatric, fever, dengue fever, infections, respiratory.

1. MD, Residente de Pediatría, Universidad Surcolombiana, Neiva, Colombia

2. MD, Pediatra, Universidad Surcolombiana, Neiva, Colombia

3. MD, profesora Universidad Surcolombiana, Neiva. Directora servicio de Infectología pediátrica Hospital Universitario Hernando Moncaleano Perdomo, Neiva, Colombia.

Datos de contacto: Doris Salgado, correo electrónico: paancaes12@hotmail.com

Recibido: 31/12/2013 - Revisado: 28/04/2014 - Aceptado: 29/06/2014 


\section{Introduccion}

El síndrome febril constituye una entidad frecuente en los servicios de urgencias pediátricas de cualquier complejidad, afectando con mayor frecuencia a los menores de 5 años y alcanzando un 10 a $30 \%$ de las atenciones, siendo las infecciones la causa más importante.

En muchas ocasiones la causa de la fiebre no es clara, induciendo la realización de pruebas diagnósticas múltiples, lo que genera angustia en los padres, además de altos costos de atención en salud.

La enfermedad febril es más común en pacientes de 3 a 36 meses y es generalmente de origen viral o benigno ${ }^{[1]}$. Las infecciones de tracto respiratorio, gastrointestinales y urinarias, de origen bacteriano pueden, en este grupo, conducir a cuadros de sepsis. Las enfermedades respiratorias y gastrointestinales continúan siendo las principales causas de morbi-mortalidad a nivel mundial y junto a las infecciones del tracto urinario juegan un papel importante en cuadros de sepsis.

En 2011, la OMS reporto la muerte de 6,9 millones de niños menores de 5 años, $58 \%$ de estas causas de mortalidad son enfermedades infecciosas, donde la neumonía, la diarrea y la malaria representaron el $36 \%$ de todas las muertes en el mundo ${ }^{[2]}$.

Es prioritario conocer el comportamiento de las diferentes infecciones en nuestra región, con el fin de poder hacer un mejor abordaje en el estudio y manejo del niño febril, considerando que en la región no hay estudios que permitan identificar el comportamiento epidemiológico de la circulación de los diferentes agentes infecciosos a lo largo del año, a excepción del virus dengue, el cual es ampliamente monitorizado.El dengue continúa siendo una de las patologías infecciosas con mayor impacto en Colombia con especial interés en salud pública, debido a la morbilidad y mortalidad en la población infantil.El Huila fue el departamento que más reporto casos de dengue grave en el 2012, según reporte del Instituto Nacional de Salud ${ }^{[3]}$.

Se realiza una descripción de la etiología del síndrome febril agudo en niños de 1 mes a 5 años atendidos en el servicio de urgencias del Hospital Universitario Hernando Moncaleano Perdomo de Neiva entre julio de 2012 y junio de 2013

\section{Material y métodos}

Se realizó un estudio descriptivo, prospectivo que incluyo pacientes de 1 mes a 5 años de edad que consultaron al servicio de urgencias pediátricas del Hospital Universitario Hernando Moncaleano Perdomo de Neiva entre julio de 2012 y junio de 2013.
Se Ingresaron pacientes con cuadro febril de 48 a 168 horas, que fueron hospitalizados y cuyos padres aceptaran participar en el estudio. Se excluyeron pacientes con imposibilidad de seguimiento, neoplasias, patología crónica o inmunodeficiencias.

Se tomaron pruebas de Laboratorio clínico necesarias para estudio de síndrome febril agudo, dependiendo de la sintomatología tales como: Hemograma, parcial de orina, urocultivo, hemocultivo, coprocultivo, cultivo de secreción de piel, estudio de líquido cefalorraquídeo (LCR), proteína $\mathrm{C}$ reactiva (PCR), prueba rápida dengue, $(\lg \mathrm{G} / \mathrm{lgM}+\mathrm{NS} 1 \mathrm{Ag})$ y Elisa $\operatorname{IgM}$ PANBIO ${ }^{\circledR}$ para dengue, de acuerdo a las técnicas estandarizadas en el laboratorio clínico del Hospital Universitario de Neiva. Se realizo panel viral para detección de Virus Respiratorios con la prueba Light Diagnostics ${ }^{\mathrm{TM}}$ Respiratory Panel 1 Viral Screening and Identification Kit, con técnica de inmunofluorescencia indirecta y rota-test, en el laboratorio de la Universidad Surcolombiana, además imágenes diagnosticas según el foco infeccioso.

La información recolectada se ingresó a una base de datos en el programa Excel y el análisis en SPSS versión 20.

Se hizo un análisis univariado en cada uno de los diagnósticos principales. Para las variables numéricas se utilizó media y rango intercuartílico.

El estudio fue financiado por la Universidad Surcolombiana, ninguno de los participantes tiene conflictos de interés y el protocolo fue aprobado por el comité de Ética e investigaciones del Hospital Universitario de Neiva.

\section{Resultados}

Un total 650 pacientes de 1 mes a 5 años de edad fueron incluidos en el estudio, de los cuales 389 cursaron con diagnóstico de síndrome febril agudo sin sintomatología respiratoria y 261 con síntomas respiratorios (Figura 1).

Las variables analizadas de acuerdo a las patologías se muestran en la Tabla 1.

El 72\% de los niños pertenecían al rango de edad entre 4 a 36 meses, el $18 \%$ de 37 a 71 meses, y el $11 \%$ de 1 a 3 meses. Se destaca el predominio del género femenino en las infecciones del tracto urinario y el masculino para las enfermedades diarreicas. La duración de la fiebre al ingreso fue mayor en los niños con dengue mientras que los cuadros más cortos se observaron en la IVU y mayor estancia en la infección de piel y tejidos blandos.

El 79\% de los pacientes provenían de la zona urbana de Neiva, el número restante a municipios cercanos (Figura 2).

Tabla 1. Principales variables de cada uno de los grupos sindromáticos

\begin{tabular}{|c|c|c|c|c|c|}
\hline Variable & $\begin{array}{l}\text { Respiratorio } \\
(n=261)\end{array}$ & $\begin{array}{l}\text { Dengue } \\
(n=143)\end{array}$ & $\begin{array}{c}\text { EDA } \\
(n=90)\end{array}$ & $\begin{array}{c}\text { IVU } \\
(n=71)\end{array}$ & $\begin{array}{l}\text { Piel y TB } \\
(\mathbf{n = 3 1})\end{array}$ \\
\hline Género & $M: 52 \%$ & $F: 54 \%$ & $M: 57 \%$ & F: $56 \%$ & $M: 58 \%$ \\
\hline Grupo etáreo predominante & 4 a 36 meses & 4 a 36 meses & 4 a 36 meses & 4 a 36 meses & 4 a 36 meses \\
\hline Mayor frecuencia & Marzo, Abril & Julio & Constante & Constante & Diciembre, Enero. \\
\hline Días * estancia & $4,9(0-30)$ & $3,5(1-21)$ & $3,6(1-16)$ & $4,9(1-17)$ & $5,3(1-15)$ \\
\hline Concurrencia & EDA viral & EDA viral & IRA no neumónica & EDA viral & EDA viral \\
\hline Mortalidad & 2 & 0 & 0 & 0 & 0 \\
\hline
\end{tabular}

*Valores son Medias (intervalo de confianza 95\%)

$M$ : masculino F: Femenino 
PACIENTES INGRESADOS AL ESTUDIO: 650

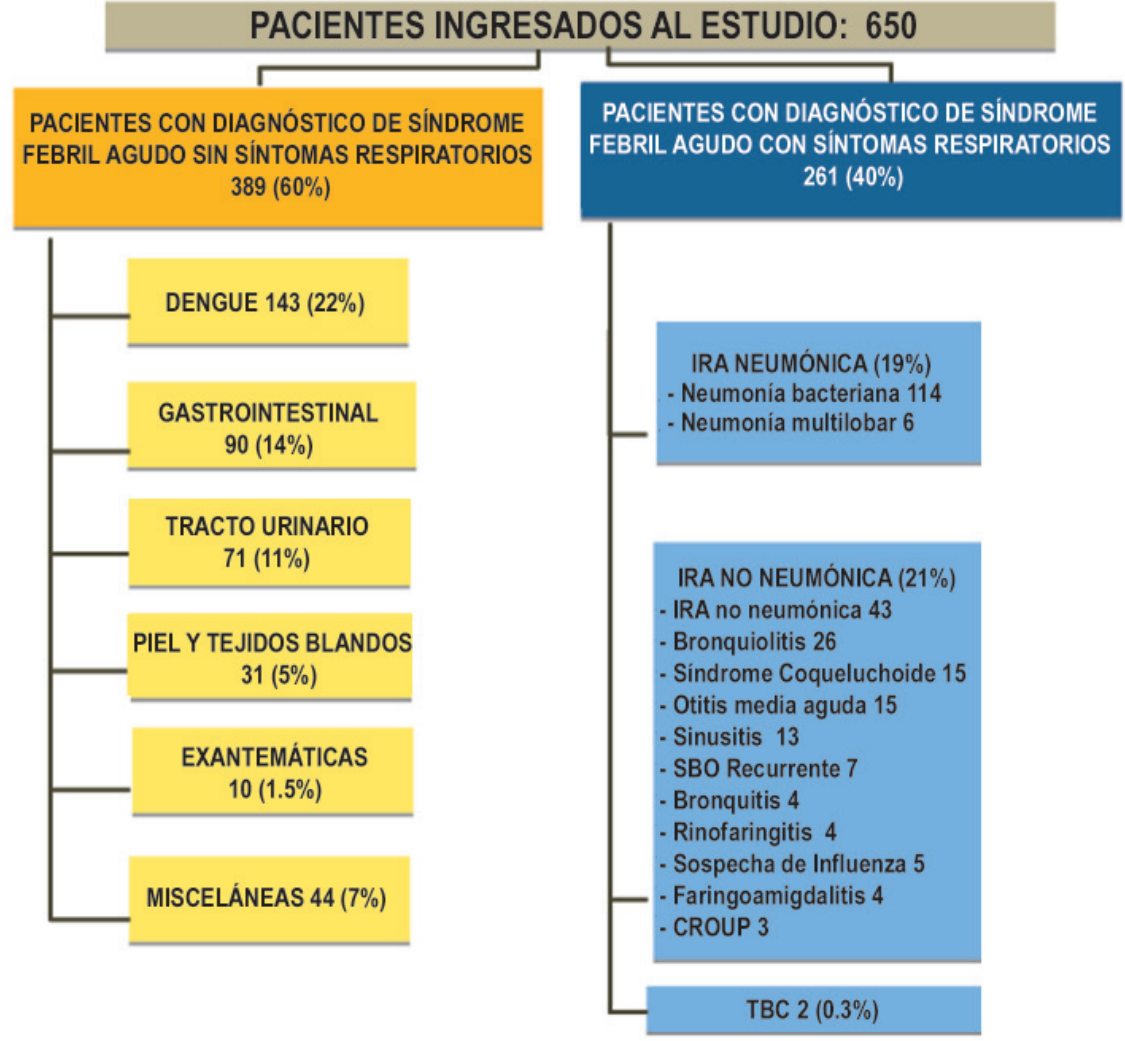

Figura 1. Pacientes ingresados.

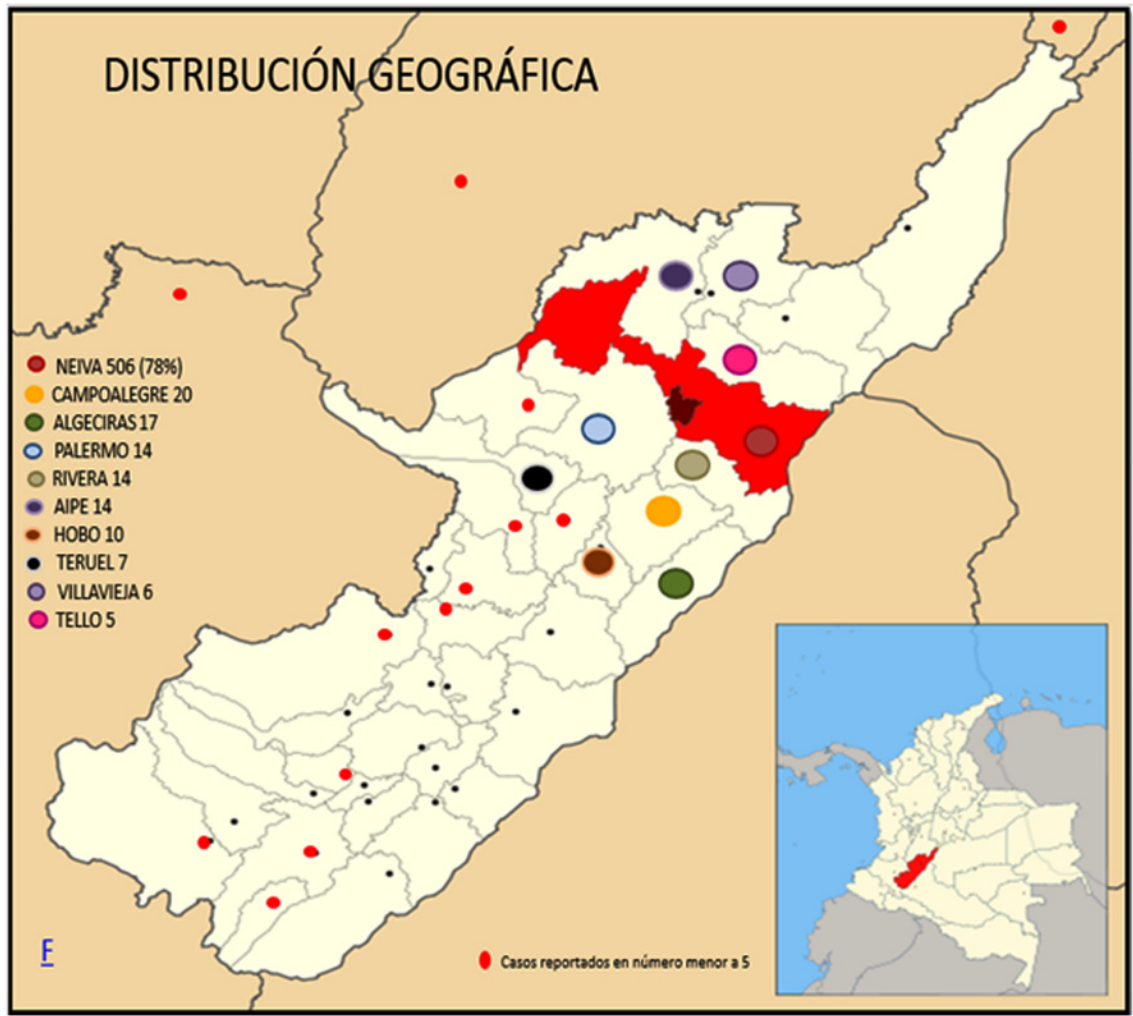

Figura 2. Procedencia. 
Se observó en los meses de marzo y abril pico de infección respiratoria (Figura 3). En el 55\% de los casos, los pacientes tenían vacunación completa para Neumococo.

De 207 pruebas realizadas para establecer el diagnostico etiológico viral, mediante técnica de inmunofluorescencia indirecta, de infección respiratoria fueron positivas el $42 \%$ y el agente causal que predomino fue VSR (46\%), seguido de parainfluenza $27 \%$, influenza A $23 \%$ y adenovirus $3 \%$. No se demostró virus de Influenza B.

En la Figura 4 se observa el comportamiento de la circulación de los virus durante el año de estudio, en el municipio de Neiva. Resalta el pico del VSR en el mes de abril y la persistencia del virus Influenza A durante los meses de enero a marzo.

La concurrencia más frecuente de las infecciones respiratorias fue enfermedad diarreica aguda en 37 casos, dentro de los cuales se incluye una infección por rotavirus. Se presentaron 2 casos de mortalidad, una neumonía con falla ventilatoria y estafilococcemia y un síndrome coqueluchoide o con prueba para Tosferina de inmunofluorescencia indirecta y VSR positivas.

143 pacientes fueron hospitalizados con diagnóstico de dengue, $87 \%$ como dengue con signos de alarma y $13 \%$ dengue grave, siendo la fuga plasmática severa y choque su mayor causa. Durante el estudio, no hubo letalidad.

Se realizaron 58 pruebas rápidas NS1 dengue, resultando 55\% positivas, la serología IgM al sexto día, tuvo una positividad del 91\%.La correlación entre las dos pruebas mostro sensibilidad del $60 \%$ (IC 95\% 0.48-0.75) y Especificidad del 100\%, (IC 95\% 1-1), con un valor predictivo positivo (VPP) del $100 \%$ y un valor predictivo negativo (VPN) del 0.2 , con kappa de 0,88 .

La etiología viral de la EDA se consideró en los $60 \%$ basados en los hallazgos del coproscópico. E1 55\% de los niños tenía vacuna contra rotavirus; en 4 casos se demostró rotavirus con antecedente de vacunación completa, 3 de estos casos eran menores de 24 meses. 1 caso de EDA evoluciono a Síndrome Hemolítico Urémico.

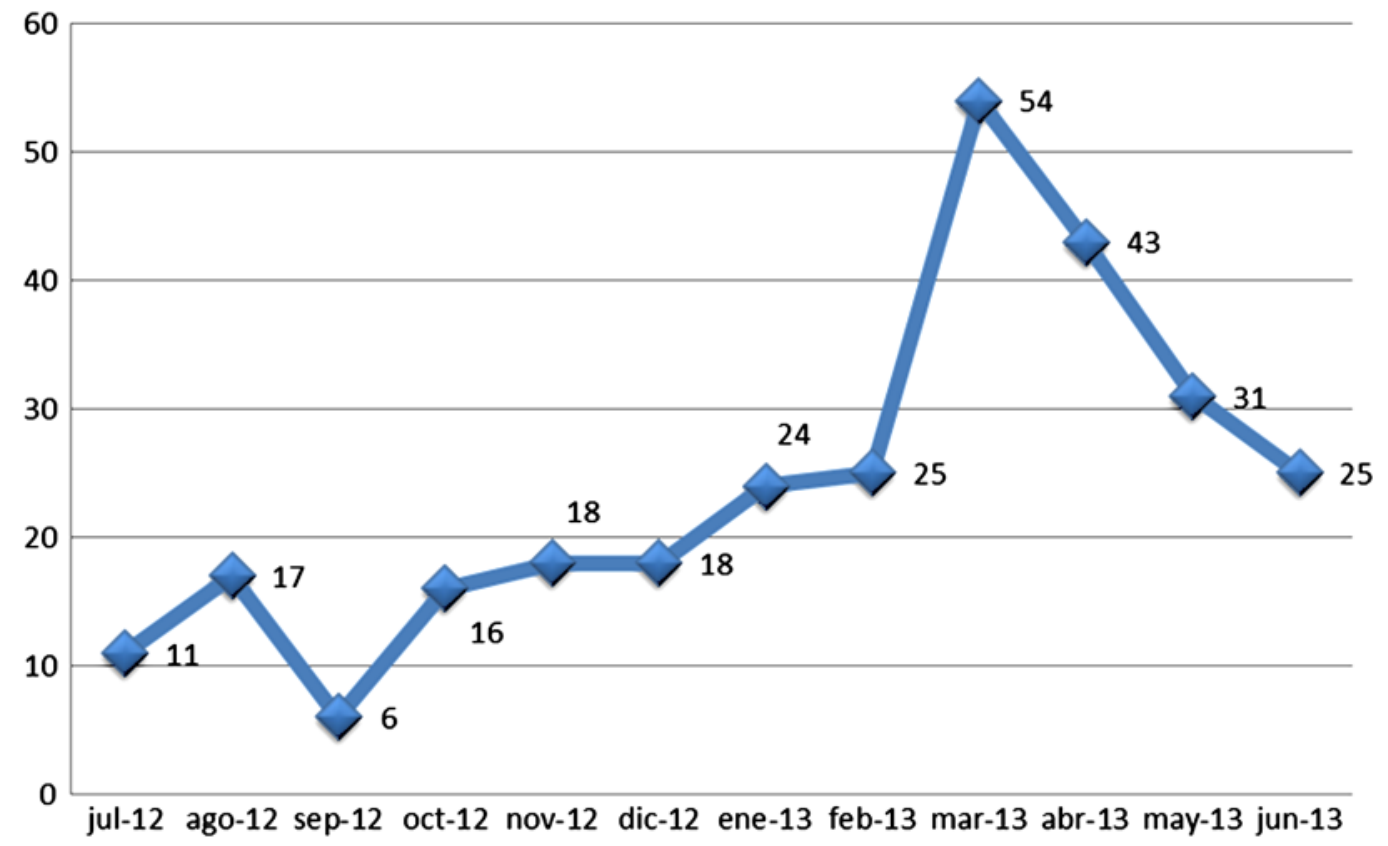

Figura 3. Respiratorio, mes de consulta.

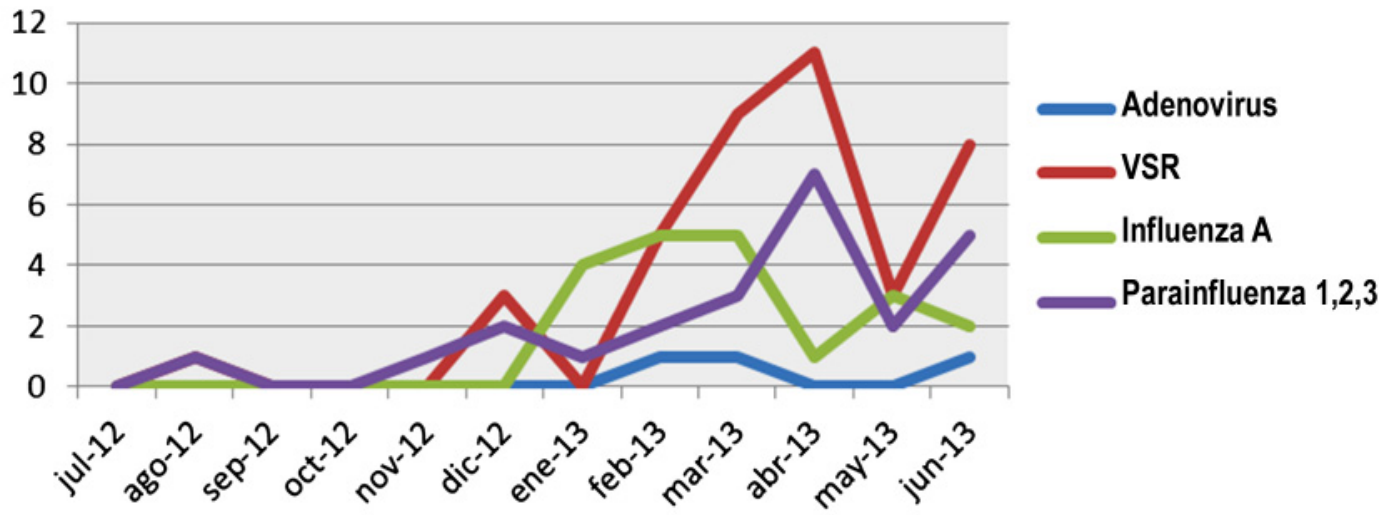

Figura 4. Circulación mensual de los virus respiratorios aislados. 
En las infecciones del tracto urinario, los urocultivos de mostraron E. coli en el $75 \%$, de las cuales el $6 \%$ fueron BLEA positivo, seguido por Proteusmirabilis y Klebsiella pneumoniae en igual proporción. En $87 \%$ de los casos de infección del tracto urinario se utilizó Ceftriaxona como tratamiento.

La celulitis en cara fue la infección de piel y tejidos blandos más frecuente, seguido por celulitis en tórax, glúteos y extremidades superiores en igual proporción. Se realizaron 11 aislamientos en cultivos de secreción, lográndose identificar al Staphilococus auerus meticilino resistente (SAMR) de la comunidad como el germen más frecuente, correspondiendo al $75 \%$. El antibiótico más utilizado fue Clindamicina y en segundo lugar Vancomicina.

Se presentaron 4 casos de enfermedad de Kawasaki, 3 meningoencefalitis bacterianas, con aislamiento de salmonella en un caso. Se documentaron 10 enfermedades exantemáticas, siendo la más frecuente varicela, incluso en uno de los casos en asociación con dengue.

\section{Discusión}

A nivel de Latinoamérica existen estudios que centran la búsqueda de la etiología del síndrome febril agudo en pacientes menores de 36 meses de edad, mostrando que la mayoría son debidas a infecciones virales auto-limitada que no requieren tratamiento específico y resuelven sin dejar secuelas Como lo plantea Jeffrey R. Avner. Entre el 10 al 25\% puede cursar con alguna infección bacteriana severa ${ }^{[4]}$.

Se ha producido un cambio importante tanto en la incidencia y la epidemiología de la bacteriemia oculta producto de la vacunación masiva contra Haemophilus influenzae y Streptococcus pneumoniae, la cual ha disminuido a un $1,5 \%{ }^{[2]}$.

De acuerdo a lo encontrando en el estudio, el grupo de niños de 4 a 36 meses presento el mayor número de casos clínicos independiente de la causa de enfermedad tal y como lo reporta la literatura mundial ${ }^{[2]}$.

Se demostró que el $30 \%$ de la consulta pediátrica fue por síndrome febril, de acuerdo a lo referido en la guía clínica NICE sobre Enfermedad febril en niños, entre el $20 \%$ y el $40 \%$ de los niños en los distintos rangos de edad son llevados a consulta debido a fiebre, con proporciones más altas entre los 6 y 18 meses. Se ha estimado que un promedio de ocho episodios infecciosos ocurren en niños por lo demás sanos durante los primeros 18 meses de vida ${ }^{[5]}$.

La literatura reporta a los virus como los principales agentes causales ${ }^{[6]}$, lo que se asemeja a lo encontrado en el presente estudio, en el que los virus fueron los causantes de fiebre en la mitad de la población estudiada $(50.6 \%)$.

Las enfermedades respiratorias continúan siendo la principal causas de morbimortalidad a nivel mundial según OMS, situación similar a lo observado en el presente estudio. Los niños menores de 5 años de edad, sufren hasta 6 episodios de IRA en un año, con mayor incidencia en aquellos menores de 2 años y 1,4 episodios de neumonía antes de cumplir los 5 años. Estas enfermedades infecciosas causan morbilidad entre los niños que viven en poblaciones de alto riesgo (Pobreza y atención de salud inadecuada), constituyendo una de las principales causas de mortalidad infantil, donde la mayoría de las muertes ocurren en niños menores de 2 años ${ }^{[7,8]}$.

En el presente estudio las infecciones del tracto respiratorio fueron la primera causa asociada a fiebre, $(40 \%)$ correlacionado con lo mencionado por la OMS. La neumonía adquirida en la comunidad fue el diagnóstico de egreso prevalente, sin demostración microbiológica dada la baja sensibilidad de los hemocultivos como tradicionalmente ha sido referido ${ }^{[9]}$.

La literatura reporta que la mayoría de los casos de IRA febriles $(80-90 \%)$ son causadas por agentes virales (Adenovirus, virus respiratorio sincicial, virus Para influenza A y B), con sólo casos ocasionales causados por bacterias (Streptococcus pneumoniae, Haemophilus influenzae y Streptococcus pyogenes) ${ }^{[10]}$. Este estudio demostró etiología viral en el $42 \%$ de los casos de IRA febril.

El VSR es el principal agente etiológico de las infecciones respiratorias agudas que requiere hospitalización, detectándose esta infección en un rango que oscila entre el $40 \%$ y $70 \%$ de los niños hospitalizados ${ }^{[11]}$. Los resultados de este trabajo coinciden con la literatura al respecto, ya que se identificó al virus respiratorio en 40 casos $(46 \%)$.

El porcentaje de hospitalización por compromiso del tracto respiratorio es cercano al $27 \%$ en niños menores de 5 años en los EE.UU. Observándose un porcentaje mayor en la población de estudio que correspondió al 36\%. Simultáneamente con estos datos, se documenta que casi dos millones de niños mueren cada año por infecciones respiratorias agudas y la mayoría de estos niños viven en países en vías de desarrollo ${ }^{[9]}$, correspondiendo al $28,5 \%$ de la mortalidad total en los niños menores de 5 años ${ }^{[12]}$. En este estudio se presentaron dos casos de muerte por causa respiratoria.

Frecuentemente las infecciones del tracto respiratorio, se reportan en picos estacionales durante el año, relacionados principalmente con los cambios climáticos (Estaciones) que producen brotes en las épocas de mayor humedad ambiental y asociadas a factores como hacinamiento, desnutrición, contaminación ${ }^{[13]}$. A nivel mundial, la estacionalidad de los agentes respiratorios varía geográficamente, de acuerdo a la temperatura predominante. Se ha demostrado que los rinovirus son la causa más común de enfermedad respiratoria viral, están presentes todos los meses del año, con picos en otoño y primavera. El virus sincicial respiratorio e Influenza predominan en invierno y principios de primavera, parainfluenza al final de otoño hasta el invierno.

En Latinoamérica, continúa prevaleciendo el virus sincicial respiratorio, en co-circulación con virus influenza H3N2 ${ }^{[14]}$. En Colombia, se presentó un decremento del $43 \%$ del número de casos de influenza AH1N1respecto al año anterior, predominando el virus, con pico estacionales (abril y mayo) ${ }^{[15]}$. Este estudio identificó a los meses marzo y abril como los de mayor presentación de casos, lo cual se correlaciona con los datos nacionales reportados.

La Organización Mundial de la Salud y la Organización panamericana de la salud estiman que la Tosferina es una causa importante de morbilidad y mortalidad infantil con un estimado de 50 millones de casos y 300.000 defunciones anuales a nivel global. La tasa de letalidad en países en desarrollo puede llegar hasta un $4 \%$ en los lactantes menores de 12 meses, por lo cual se considera una de las principales causas de muerte evitables mediante vacunación, la cual se espera pueda ser ampliada y la estrategia capullo de la OMS pueda cambiar estos resultados. En el estudio, el síndrome coqueluchoide representó el 6\%, con una letalidad de $6 \%$.

La literatura sugiere que la diarrea ha contribuido sustancialmente con el riesgo de Infección Respiratoria en pocas semanas de su ocurrencia ${ }^{[16]}$, de igual manera se ha demostrado que los niños que sufren episodios repetidos o graves de diarrea están en riesgo más alto de sufrir una infección del tracto respiratorio ${ }^{[16,}$

17]. Haciendo correlación a estos datos, en el estudio se identificó a la enfermedad diarreica aguda como la principal concurrencia no solo de las infecciones del tracto respiratorio sino también de todas las patologías descritas. 
El nexo causal entre diarrea y el consiguiente riesgo de IRA es por lo tanto, de considerable importancia para la salud pública debido a que intervenciones efectivas dirigidas a enfermedades diarreicas podría contribuir a una reducción de las infecciones respiratorias y por consiguiente en la mortalidad infantil.

El presente estudio mostro al dengue en segundo lugar como causa de fiebre desplazando a las EDAS y marcando una diferencia de lo planteado en la literatura demostrando la importancia de las particularidades epidemiológicas locales.

El dengue continúa siendo una de las patologías infecciosas con mayor impacto en salud pública. El Huila ha sido uno de los departamentos con mayor número de casos registrados, sobre todo en las formas graves (13\%), por encima de lo reportado en la literatura mundial, donde se estima que al menos $10 \%$ de los casos de fiebre de dengue evolucionan a formas graves y eventualmente letales. Estos pacientes finalmente recibieron manejo en unidad de cuidado intensivo pediátrico sin presentar mortalidad.

A pesar de que en año 2010 Colombia sufrió la mayor epidemia de los últimos años, en el Huila y algunos departamentos de Colombia se presentó de nuevo brote a lo largo de todo el año 2012 (SIVIGILA 2010 y 2012) ) $^{[3]}$, modificando lo descrito tradicionalmente en cuanto a que los brotes epidémicos eran cada 5 años en promedio, la situación epidémica del dengue ha cambiado, los casos han crecido exponencialmente y los periodos inter-epidémicos se han acortado, es el caso del Huila como se evidencio en este Estudio.

Para el diagnóstico de dengue, aparte de la serología, se realizó la prueba rápida, con determinación del NS1, la correlación de las dos pruebas mostró una Sensibilidad del 60\% (IC 95\% 0.48-0.75), y una Especificidad del 100\%, (IC 95\% 1-1), con un valor predictivo positivo (VPP) del 100\% para NS1 .Estos resultados se correlacionan con la literatura, en cuanto a la especificidad de las pruebas NS1 Dengue con reportes que oscilan entre 86 y $100 \%$ y los falsos positivos son considerados raros. Se ha informado de igual manera, una mayor variabilidad de la Sensibilidad (entre 37\% y 98,9\%) en varios ensayos. Esta variabilidad podría explicarse en parte por el momento de la toma pues disminuye con el tiempo transcurrido desde el inicio de la fiebre y en las infecciones secundarias ${ }^{[18]}$.

La enfermedad diarreica aguda sigue siendo una patología prevalente a nivel mundial en países de bajos y medianos ingresos, los niños menores de 5 años experimentan múltiples episodios de diarrea cada año ${ }^{[17]}$. Similar con lo reportado en la literatura, este estudio evidenció que la enfermedad diarreica aguda corresponde a la tercera causa de egreso, siendo la etiología viral la más frecuente, como ha sido referido en otras series ${ }^{[19]}$.

Se presentaron 4 casos de infección por rotavirus, en pacientes previamente inmunizados. Estos pacientes podrían pertenecer al grupo que no hace una respuesta completa a la inmunización, dado que la eficacia de la vacuna contra la gastroenteritis por rotavirus G1-G4 de cualquier gravedad es del 74\%, mientras que la eficacia contra el enfermedad grave es aproximadamente $98 \%{ }^{[20]}$. La magnitud de esta infección ha disminuido respecto a los años previos dado el uso cada vez mayor de la vacuna anti-rota vírica en lactantes [21]. En Colombia es sistemática desde el año 2009.

La infección del tracto urinario es una de las infecciones más comunes en la edad pediátrica con indicación clara para ingreso hospitalario ${ }^{[22]}$. En los aislamientos de los urocultivos, el $75 \%$ de los casos correspondió a Escherichia coli, seguido por Proteus mirabilis y Klebsiella pneumoniae, lo cual se correlaciona con lo referido en la literatura ${ }^{[22]}$. El Conocimiento del patrón de resisten- cia local a los antibióticos, es importante para reducir los fracasos terapéuticos, y hacer vigilancia epidemiológica ${ }^{[23]}$.

El staphilococcus aureus meticilino resistente de la comunidad fue el principal agente aislado en las infecciones de piel y tejidos blandos en este estudio con el 75\%, relacionándose con datos históricos del servicio de pediatría en los últimos 5 años, así como con la literatura ${ }^{[24]}$. En las infecciones de piel y tejidos blandos, el estafilococo de la comunidad ha mostrado en los últimos años cambios en sus factores de virulencia, especialmente relacionados con el comportamiento frente a los antibióticos, lo que ha generado una nueva mirada al tratamiento de estas infecciones ${ }^{[24]}$. Y es así como el uso de clindamicina se ha triplicado $(30 \%$ de los casos en 1999vs89\%en 2008), frente a la disminución de los b-lactámicos. (78\% en 1999 frente al $11 \%$ en 2008) ${ }^{[25]}$.

La enfermedad de Kawasaki de distribución mundial, de mayor prevalencia en niños de origen Japonés y Asiático, donde el número de casos alcanza los 184/100.000 habitantes; es endémica con fluctuaciones temporales y brotes epidémicos ${ }^{[26]}$. En el periodo de estudio, se encontraron 4 casos, número importante y relacionado a lo referido en la literatura ${ }^{[27]}$, en cuanto al incremento de los reportes de esta patología en las últimas décadas debido a un mayor reconocimiento de esta entidad que afecta con mayor frecuencia al género masculino entre 12 meses a 5 años.

\section{Conclusiones}

La demostración de la etiología viral es muy importante en niños con enfermedad febril respiratoria, por ello debe considerarse la realización de pruebas de tamizaje diagnóstico como el panel viral respiratorio, dado que la detección del agente proporciona información de utilidad para el manejo y pronostico, contribuyendo a la disminución de costos y estancias hospitalarias.

La estacionalidad de los agentes respiratorios varía de una región a otra, con este estudio se demuestra la importancia de la circulación e infección por virus sincicial respiratorio en el Huila, cuyo mayor pico ocurrió en la misma época que en el resto del país.

El uso de las pruebas antigénicas en paciente febril sin foco en zona endémica de dengue, es indudablemente de alto valor en cuanto a la especificidad y al valor predictivo positivo para el clínico porque le facilita orientación del caso, así como establecer un plan terapéutico especifico, sobre todo en niños menores de 5 años.

Es el estafilococo meticilino resistente (SAMR) de la comunidad el agente principal de las infecciones de piel y tejidos blandos y en el contexto de las tasas locales, el uso de clindamicina empíricamente es una adecuada opción, una vez se haya tomado muestra para cultivo.

La tos ferina continua ocupando un lugar importante en la mortalidad como se demostró en este estudio, por ello se deben incentivar todas las medidas que faciliten su prevención.

\section{Agradecimientos}

Al Dr. Carlos Narváez, Bacterióloga Piedad Perilla y el Laboratorio de Inmunovirología de la Universidad Sucolombiana, a la Vicerrectoría de Investigaciones de la Universidad Surcolombiana por la financiación, y a los niños que participaron en el desarrollo del estudio. 


\section{Bibliografía}

1. Avner, J.R., Acute fever. Pediatr Rev, 2009. 30(1):5-13.

2. Salud, O.M.d.I., Principales causas de muerte en los recién nacidos y niños menores de cinco años a nivel mundial. 2011.

3. Salud, I.-I.N.d., Boletín epidemiológico dengue semana 51. 2012.

4. Brockmann, V.P., et al., [Etiology of acute fever without source in infants consulting at an emergency department]. Rev Chilena Infectol, 2007. 24(1):33-9.

5. (UK), N.C.C.f.W.s.a.C.s.H., Feverish Illness in Children: Assessment and Initial Management in Children Younger than 5 Years, N. (NICE Clinical Guidelines, Editor. 2007 May: London (UK):RCOG Press.

6. Santos García García, M.R.S., Síndrome febril en el niño, in Formación Médica. 2007: Madrid.

7. Peng, D., et al., Multipathogen infections in hospitalized children with acute respiratory infections. Virol J, 2009. 6(155):6-155.

8. Calvo, C., et al., Multiple simultaneous viral infections in infants with acute respiratory tract infections in Spain. J Clin Virol, 2008. 42(3):268-72.

9. Singh, V. and S. Aneja, Pneumonia - management in the developing world. Paediatr Respir Rev, 2011. 12(1): 52-9.

10. Carranza-Martinez, M.I., et al., Clinical outcomes in Mexican children with febrile acute upper respiratory tract infections: no impact of antibiotic therapy. International Journal of Infectious Diseases. 14(9):e759-e763.

11. Sanguinetti S, R.R., Batthyáni L, Santoro A, Rubio I, Chiparelli H, Varela A, Mateos S., Infección respiratoria aguda por virus sincicial respiratorio en niños hospitalizados menores de dos años. Revista Pediátrica Uruguaya, 2006. 71:5-9

12. Walker, C.L., et al., Global burden of childhood pneumonia and diarrhoea. Lancet, 2013. 381(9875): 1405-16.

13. Viegas, M., et al., Respiratory viruses seasonality in children under five years of age in Buenos Aires, Argentina: a five-year analysis. J Infect, 2004. 49(3):222-8.

14. Monto, A.S., Epidemiology of viral respiratory infections. Am J Med, 2002. 22(1 12):4S-12S.
15. Salud, I.-I.N.d., Existe circulación estacional del virus de Influenza A H1N1 / 09 conjuntamente con otros virus respiratorios. 2013, Noticias: Bogotá. Colombia.

16. Schmidt, W.P., et al., Recent diarrhoeal illness and risk of lower respiratory infections in children under the age of 5 years. Int J Epidemiol, 2009. 38(3):766-72.

17. Walker, C.L., et al., Diarrhea as a risk factor for acute lower respiratory tract infections among young children in low income settings. J Glob Health, 2013. 3(1): 010402.

18. Osorio, L., et al., Comparison of the diagnostic accuracy of commercial NS 1-based diagnostic tests for early dengue infection. Virol J, 2010. 7(361):7-361.

19. Alter, S.J., et al., Common childhood bacterial infections. Curr Probl Pediatr Adolesc Health Care, 2011. 41(10): 256-83.

20. Vesikari, T., et al., Safety and efficacy of a pentavalent human-bovine (WC3) reassortant rotavirus vaccine. $\mathrm{N}$ Engl J Med, 2006. 354(1):23-33.

21. Delayed onset and diminished magnitude of rotavirus activity-United States, November 2007-May 2008. MMWR Morb Mortal Wkly Rep, 2008. 57(25):697-700.

22. Shaikh, N., et al., Prevalence of urinary tract infection in childhood: a meta-analysis. Pediatr Infect Dis J, 2008. 27(4):302-8.

23. Wong, S.N., et al., Evaluating different imaging strategies in children after first febrile urinary tract infection. Pediatr Nephrol, 2010. 25(10):2083-91.

24. Como-Sabetti, K., et al., Community-associated methicillin-resistant Staphylococcus aureus: trends in case and isolate characteristics from six years of prospective surveillance. Public Health Rep, 2009. 124(3):427-35.

25. Stevens, D.L., et al., Practice guidelines for the diagnosis and management of skin and soft-tissue infections. Clin Infect Dis, 2005. 41(10):1373-406.

26. James Cherry, G.D.-H., Sheldon Kaplan, William Steinbach, Peter Hotez, Feigin and Cherry's Textbook of Pediatric Infectious Diseases. 6th ed, ed. s.X. Kawasaki disease. Part II, chapter 88. 2009.

27. Yeung, R.S., Kawasaki disease: update on pathogenesis. Curr Opin Rheumatol, 2010. 22(5):551-60. 